\title{
High School Students' Difficulties in Making Mathematical Connections when Solving Problems
}

\author{
Jailani, Heri Retnawati and Ezi Apino \\ Universitas Negeri Yogyakarta (Yogyakarta State University), \\ Yogyakarta, Indonesia \\ https://orcid.org/0000-0001-5552-255X \\ https:// orcid.org/0000-0002-1792-5873 \\ https://orcid.org/0000-0001-9711-2807 \\ Agus Santoso \\ Universitas Terbuka (Open University) \\ South Tangerang, Banten, Indonesia \\ https://orcid.org/0000-0003-3696-2132
}

\begin{abstract}
The primary purpose of studying mathematics is that students can solve problems, both mathematical and real-life problems. In this way, mathematical connections play an essential role in enabling students to solve mathematical problems. Students' difficulties in mathematical connections can cause difficulties in solving problems. This study aims to describe the mathematical connections difficulties experienced by students when solving mathematical problems. This study is qualitative with a phenomenological approach. Data were collected by using mathematical connection tests and interviews after the test. The participants of this study were 31 high school students from five schools in Yogyakarta Special Region and Central Java Province, Indonesia. Data analysis began with analyzing all students' answers in solving mathematical problems and categorizing the types of difficulties experienced by students. Thematic analysis of the interview data was conducted to reveal the causes of difficulties experienced by students when making mathematical connections. The findings showed that most students experienced difficulties in making mathematical connections, such as in different representations, part-whole relationships, connections between mathematical concepts, and interrelationships between mathematical procedures. Several causes of such difficulties and further actions were also discussed in this study.
\end{abstract}

Keywords: mathematical connections; mathematical problem-solving; students' difficulties; mathematics learning; phenomenological study 


\section{Introduction}

Mathematics is a compulsory subject learned from primary to higher education. This subject plays an essential role in the advancement and development of science and technology, and also contributes directly to human survival. Besides, mathematics is not just arithmetic, but it can also be used to practice a variety of thinking skills, such as critical thinking (Appelbaum, 2000; Lince, 2016; Suh \& Seshaiyer, 2013), creative thinking (Leikin \& Pitta-Pantazi, 2013; Lince, 2016), logical thinking (Hodge, 2003; Lince, 2016), and higher-order thinking skills (Apino \& Retnawati, 2017, 2019). The importance of mathematics encourages many countries to keep creating innovations in strategies and approaches to learning mathematics to make mathematics more understandable and applicable in real-life situations.

One of the keys to learning mathematics is problem-solving (NCTM, 2000; Palmér \& Van Bommel, 2020; Van Zanten \& Van den Heuvel-Panhuizen, 2020). Problemsolving is in line with the spirit of mathematics as a means to develop thinking skills. In the context of mathematics education, this problem solving is used to introduce and familiarize students with how to understand a phenomenon related to mathematical concepts and things associated with the application of mathematics in everyday life (Osman et al., 2018). By using problem-solving, the students are then expected to be able to plan and find solutions to various problems systematically and logically (Albay, 2019). This ability is fundamentally important as it can help the students face increasingly complex challenges in life.

Many kinds of literature categorize problem-solving as one of the competencies that must be possessed for success in the 21st century besides critical thinking, creativity, collaboration, and communication (Albay, 2019; English \& Gainsburg, 2016; Partnership for 21st Century Learning, 2019). Today, problem-solving is no longer seen as a written skill, but from a broader perspective, it evolves into an essential skill used to compete in the world of work and even to answer the challenges of this era. In order to reach this skill, other abilities are needed. As formulated by NCTM (2000), in mathematics learning standards, another ability such as mathematical connection must be practiced by students in addition to problem-solving. NCTM (2000) highlights that the mathematical connection is a tool for problem-solving. Mathematical connections help students recognize and use relationships between mathematical ideas and use them in different contexts (Dolores-Flores, Rivera-López \& García-García, 2019). Having strong mathematical connections will also enhance mathematical understanding (GarcíaGarcía \& Dolores-Flores, 2018; Kenedi, Helsa, Ariani, Zainil \& Hendri 2019; Silver, Mesa, Morris, Star \& Benken, 2009) and student achievement (Kartikasari \& Widjajanti, 2017; Ndiung \& Nendi, 2018). Hence, making mathematical connections is necessary for students to be successful in mathematics education.

Mathematical connections are generally associated with three things, namely connections related to the application of mathematics to real-life contexts (Blum, Galbraith, Henn \& Niss, 2007; Monroe \& Mikovch, 1994; Mwakapenda, 2008; Özgen 2016), mathematical connections with other disciplines (Blum et al., 2007; Mwakapenda, 2008; Özgen 2016), and connections between mathematical ideas 
or concepts themselves (Blum et al., 2007; Eli, Mohr-Schroeder \& Lee, 2013; Monroe \& Mikovch, 1994; Mwakapenda, 2008). The connection between mathematical ideas or concepts by Businskas (2008) is referred to as interconnections in mathematics, while García-García and Dolores-Flores (2018) mention them as intra-mathematical connections. The ability to make connections between mathematical ideas or concepts themselves (interconnections or intramathematical connections) is crucial for understanding mathematical concepts (Anthony \& Walshaw, 2009; Berry \& Nyman, 2003; García-García \& DoloresFlores, 2020; Mhlolo, 2012) and for their application to other scientific disciplines (Mhlolo, 2012; Mhlolo, Venkat \& Schäfer, 2012). Thus, interconnection in mathematics becomes an interesting topic to discuss. Businskas (2008) suggests that most literature only focuses on examining the connection between mathematics and real-world situations without exploring how interconnection in mathematics itself. Besides, García-García and Dolores-Flores (2020) reveal that there is still little research focused on investigating the mathematical connection process when students solve mathematics problems. Hence in this study, mathematical connections are focused on interconnection in mathematics itself when students solve mathematical problems.

Businskas (2008) suggests a framework for thinking about mathematical connections in practice. The framework of thinking can be operationally used as an indicator of mathematical interconnections consisting of five categories. The categories include (1) different representation as a form of mathematical connections; (2) part-whole relationships; (3) connections where A implies B; (4) connections showing that $\mathrm{A}$ is a procedure for doing $\mathrm{B}$; and (5) instructional oriented connection that shows how certain concepts are pre-requisites for understanding related concepts (Businskas, 2008). García-García and DoloresFlores develop a framework similar to Businskas and have implemented it in their research (e.g., García-García \& Dolores-Flores, 2018; 2020). That framework includes several types of mathematical connections indicators, including the following: different representations, procedural features, reversibility, and meaning as a connection. Through these indicators, mathematical connections can be identified more quickly and the extent to which mathematical connections can be easily measured.

Some other studies also report that the students' mathematical connection abilities at various levels need serious attention. Lapp, Nyman, and Berry (2010) report that undergraduate students encountered difficulties in making connections between various concepts, such as the connection between eigenvalues and eigenvectors in algebra learning. Dolores-Flores et al. (2019) explore the mathematical connections of pre-university students when solving tasks involving the rates of change. The result showed that the students only made mathematical connections of procedural types. In contrast, the students scarcely made other types of mathematical connections, such as the common features and the generalization. Siregar and Surya (2017) analyze the junior high school students' abilities in mathematical connections using tests of mathematical connections, and the result showed that their abilities were still low. Similarly, Kenedi et al. (2019) investigate the elementary school students' mathematical connection ability in solving mathematics problems, and the result showed that 
their abilities were also low. The results of these studies can be used as a basis for improving the quality of mathematics learning that is oriented towards enhancing mathematical connections.

In practice, several studies report some obstacles in teaching mathematical connections. Dolores-Flores et al. (2019) report that a lack of conceptual understanding and difficulties in manipulating algebra were the main obstacles in making mathematical connections. Arjudin, Sutawidjaja, Irawan, and Sa'dijah (2016) also report that students' difficulties in making mathematical connections were caused by errors in connecting with conceptual knowledge and procedural knowledge. Lack of familiarity with the mathematical connection problems also becomes another obstacle for students in developing their mathematical connection ability. In this way, Agustini, Suryadi, and Jupri (2017) suggest familiarizing students with mathematical connection problems by using openended problems. These findings indicate that actions are needed to improve the quality of mathematics learning, which is oriented towards strengthening mathematical connection skills.

The starting point for improvement can be made by identifying students' difficulties in solving mathematics problems (Hadi, Retnawati, Munadi, Apino \& Wulandari, 2018; Rafi \& Retnawati, 2018; Wijaya, van den Heuvel-Panhuizen, Doorman \& Robitzsch, 2014). In this context, we view that investigating student difficulties when making mathematical connections in solving mathematical problems is urgent. Dolores-Flores et al. (2019) point out that mathematical connections occur when students carry out specific tasks and, therefore, we can identify its processes from the writings or arguments produced by the students. Besides, García-García and Dolores-Flores (2018) argue that students have an important role in reflection for process and learning improvement related to mathematical skill connections. Thus, the findings from the results of identifying what students do in solving mathematics problems that require mathematical connection skills can be used as a reflection to improve mathematics learning.

Even though there have been many studies related to mathematical connection, there are still a few studies that are focused on investigating the difficulties experienced by students in making mathematical connections when solving mathematics problems. The study of García-García and Dolores-Flores (2018) is more focused on exploring the types of mathematical connections made by high school students in performing Calculus tasks. Furthermore, the study of GarcíaGarcía and Dolores-Flores (2020) also explores the types of mathematical connections in solving Calculus application problems but involves pre-university. Payton (2019) conducts a study that focuses on interventions that aim to develop mathematical connections. Zengin (2019) examines the use of GeoGebra software for the development of mathematical connections skills. Other studies are conducted to explore mathematical connections involving various representations (e.g., García-García \& Dolores-Flores, 2018; Mhlolo, 2012; Mhlolo et al., 2012; Moon, Brenner, Jacob \& Okamoto, 2013). Based on this review, we are motivated to explore students' difficulties in making mathematical connections, 
especially when students interconnect mathematical concepts or procedures when solving mathematics problems.

Based on the urgency and the review that has been put forward, this study aims to describe the students' difficulties in making mathematical connections when solving mathematical problems. We hope that the findings of this study can provide a framework for educators to improve best practices in mathematics learning, especially related to the development of students' mathematical connection skills.

\section{Methods}

\subsection{Type of Study}

This study was classified as phenomenology, a type of qualitative research methods. The primary aim of phenomenological research was to reduce the experiences of people with a particular phenomenon to find descriptions of the universal essence (Creswell, 2013). The phenomenon in this study was about the students' difficulties in making mathematical connections, especially in solving mathematical problems. One common phenomenon which occurred when students solved mathematical problems was that students already knew a concept, but they had difficulty in connecting the concept with other mathematical concepts. This phenomenon often harms their understanding of mathematical concepts and their academic achievement in learning mathematics.

\subsection{Participants}

The participants of this study were 31 eleventh grade high school students from five schools in Yogyakarta Special Region and Central Java Province, Indonesia. We selected the schools as representatives with high, medium, and low academic achievement. Six students came from school with high academic achievement, 21 students came from school with medium academic achievement, and 12 students came from school with low academic achievement. When we conducted the study, the students involved in this study were between 15 and 17 years old.

\subsection{Data Collection}

We collected data through tests and interviews. The test consisted of mathematical problems (items) containing concepts that had been taught at schools. It comprised of three items, and each of them required a mathematical connection ability to solve it. We took these items from the college entrance exam questions in Indonesia that had been released and re-validated. The validity of the test instrument was proven through content validation by asking experts to agree on the item's suitability with the indicators. The experts were two high school mathematics teachers and two mathematics education lecturers. The indicators of mathematical connection abilities used in this study included different representations (DR), part-whole relationships (PWR), connections where A implies B (IM), and connections showing that A is a procedure for doing B (PD). We used item 1 to measure the students' mathematical connection ability to solve the problem of a two-variable linear equation (see Figure 2). We used item 2 to measure the students' mathematical connection ability to solve the problem of a trigonometric equation (see Figure 3). We used item 3 to measure the students' 
mathematical connection ability to solve the problem of a circle (see Figure 4). Before taking the test, we informed students that the test results would not affect their academic achievement in school, but we asked them to take the test seriously. The test was not administered in the regular classroom but taken vacant or available time as agreed by the teacher, students, and researchers in each school. We gave students 30 minutes to complete the test.

We conducted interviews with the students right after they finished the test. The interviews aimed to know the students' perceptions of the problems being tested. In this case, we asked the students to show which difficult parts of the problemsolving process they found. The interviews were also focused on finding obstacles or causes of the difficulties encountered by the students in solving mathematical connection problems. Before the study, we informed the students that the tests and interviews conducted during the data collection would not affect their academic achievement at school. We conducted interviews right after all students have completed the mathematical connection test in each school. Students have interviewed alternately one by one for about 15 minutes. The answers of each student during the interview were noted directly by the researchers.

\subsection{Data Analysis}

Data analysis was preceded by analyzing the answer sheet of each student. Scoring was done by referring to the scoring guidelines prepared by researchers. The scoring guidelines contained solutions and steps for solving (procedures) that students must take when solving problems. In this study, these procedures represent indicators of mathematical connections (see Figure 2 for an example). We gave a score of 1 for each correct procedure performed by students for each mathematical connection indicator, while for the incorrect procedure, we gave a score of 0 .

In Problem 1, there were two procedures of DR, one procedure of IM, and two procedures of PD (see Figure 2). Students were categorized as "High Mastery" if they performed all the procedures correctly for each indicator. If students only performed one correct procedure on the DR and PD indicators, then students were categorized as "Average Mastery". In contrast, if all procedures performed by students did not meet the three mathematical connection indicators, then they were categorized as "Low Mastery".

In Problem 2, there were six procedures of DR, one procedure of IM, and two procedures of PD (see Figure 3). In Problem 2, if students performed at least four correct procedures on the DR indicator, students were categorized as "High Mastery". If students only performed one to three correct procedures, then they were categorized as "Average Mastery", meanwhile if all the procedures performed by students were incorrect, then students were categorized as "Low Mastery". For the IM indicator in Problem 2, the categorization of students was the same as Problem 1.

For Problem 3, there was one procedure of DR, two procedures of PWR, one procedure of IM, and three procedures of PD (see Figure 4). For DR and IM 
indicators, students were categorized as "High Mastery" if they could perform the procedure correctly. In contrast, if the procedure was incorrect, then students were categorized as "Low Mastery". For the PWR indicator, students were categorized as "High Mastery" if they performed two procedures correctly, "Average Mastery" if they performed only one procedure correctly, and "Low Mastery" if they performed all procedures incorrectly. As for the PD indicator, students were categorized as "High Mastery" if they performed three procedures correctly, "Average Mastery" if they only performed one to two procedures correctly, and "Low Mastery" if all the procedures were incorrect.

The data obtained were then tabulated based on the students' ability categories (High Mastery, Average Mastery, and Low Mastery) and mathematical connection indicators (DR, PWR, IM, and PD) for each problem. From this tabulation, we obtained the number and percentage of students for each category of ability and mathematical connection indicators for each problem. In this study, we considered students in the Average Mastery and Low Mastery categories as participants who experienced mathematical connection difficulties. Then some of their answers were selected to map the errors made by students for each mathematical connection indicator for each problem. We presented the results of the mapping narratively.

The results of the interviews were qualitatively analyzed using an analytical technique developed by Bogdan and Biklen (2007) by analyzing the relationships between themes from the qualitative data obtained from the interviews. The transcripts of the interview data were then coded independently by two researchers. If there were differences in the coding results, the two researchers together reviewed the data then agreed to determine the correct coding. If there were no differences in coding results, all researchers analyzed the relationship between the coding so that we found the sub-themes. The relationship between the sub-themes was then analyzed so that we found the main themes. We presented the thematic results of the analysis in the tables.

This study involved all researchers during the data analysis processes to ensure the validity and reliability in interpreting the qualitative data. All researchers had experienced in the field of qualitative research, especially related to educational issues. Then we discussed the results of the data analysis in a Focus Group Discussion (FGD) involving all researchers and two experts. The two experts were lecturers outside the researchers' institution and had experienced in qualitative research related to educational issues. The FGD discussed research findings and its suitability and consistency with the data obtained from participants.

\section{Results}

\subsection{Description of difficulties in students' mathematical connection ability}

In this study, we see the students' mathematical connection ability through four primary indicators, namely different representation (DR), part-whole relationships (PWR), connections where A implies B (IM), and connections showing that $\mathrm{A}$ is a procedure for doing $\mathrm{B}(\mathrm{PD})$. We categorized the ability of the students to master each of the mathematical connection indicators into three levels 
of mastery, including the following: "High Mastery," "Average Mastery," and "Low Mastery". We use the "Average Mastery" and "Low Mastery" levels as a basis for identifying students who experience mathematical connection difficulties. In other words, when the mastery of each indicator only reaches the level of "Average Mastery" and "Low Mastery," the students were then categorized as experiencing mathematical connection difficulties. We present the percentage of students who experience mathematical connections difficulties and the level of student mastery of each indicator in each problem in Table 1.

Table 1. Percentage of students experiencing mathematical connection difficulties

\begin{tabular}{|c|c|c|c|c|c|c|c|c|}
\hline \multirow{2}{*}{$\begin{array}{l}\text { Indicators of Mathematical } \\
\text { Connections }\end{array}$} & \multicolumn{2}{|c|}{$\begin{array}{c}\text { High } \\
\text { Mastery }\end{array}$} & \multicolumn{2}{|c|}{$\begin{array}{l}\text { Average } \\
\text { Mastery }\end{array}$} & \multicolumn{2}{|c|}{$\begin{array}{c}\text { Low } \\
\text { Mastery }\end{array}$} & \multicolumn{2}{|c|}{ Difficulties ${ }^{1)}$} \\
\hline & $n$ & $\%$ & $n$ & $\%$ & $n$ & $\%$ & $n$ & $\%$ \\
\hline \multicolumn{9}{|l|}{ Problem 1: } \\
\hline Different Representation (DR) & 16 & 42.11 & 7 & 18.42 & 15 & 39.47 & 22 & 57.89 \\
\hline Part-Whole Relationships (PWR) & -2) & - & - & - & - & - & - & - \\
\hline $\begin{array}{l}\text { Connections where A Implies B } \\
\text { (IM) }\end{array}$ & 10 & 26.32 & - & - & 28 & 73.68 & 28 & 73.68 \\
\hline $\begin{array}{l}\text { Connections that show that } \mathrm{A} \text { is } \\
\text { a procedure for doing } \mathrm{B}(\mathrm{PD})\end{array}$ & 17 & 44.74 & 6 & 15.79 & 15 & 39.47 & 21 & 55.26 \\
\hline \multicolumn{9}{|l|}{ Problem 2: } \\
\hline Different Representation (DR) & 18 & 47.37 & 10 & 26.32 & 10 & 26.32 & 20 & 52.63 \\
\hline Part-Whole Relationships (PWR) & $-2)$ & - & - & - & - & - & - & - \\
\hline $\begin{array}{l}\text { Connections where A Implies B } \\
\text { (IM) }\end{array}$ & 18 & 47.37 & - & - & 20 & 52.63 & 20 & 52.63 \\
\hline $\begin{array}{l}\text { Connections that show that } \mathrm{A} \text { is } \\
\text { a procedure for doing } \mathrm{B}(\mathrm{PD})\end{array}$ & 10 & 26.32 & 9 & 23.68 & 19 & 50.00 & 28 & 73.68 \\
\hline \multicolumn{9}{|l|}{ Problem 3: } \\
\hline Different Representation (DR) & 5 & 13.16 & - & - & 33 & 86.84 & 33 & 86.84 \\
\hline Part-Whole Relationships (PWR) & 1 & 2.63 & 15 & 39.47 & 22 & 57.89 & 37 & 97.37 \\
\hline $\begin{array}{l}\text { Connections where A Implies B } \\
\text { (IM) }\end{array}$ & 7 & 18.42 & - & - & 31 & 81.58 & 31 & 81.58 \\
\hline $\begin{array}{l}\text { Connections that show that } \mathrm{A} \text { is } \\
\text { a procedure for doing } \mathrm{B}(\mathrm{PD})\end{array}$ & 2 & 5.26 & 13 & 34.21 & 23 & 60.53 & 36 & 94.74 \\
\hline
\end{tabular}

Notes:

1) Difficulties in mathematical connection are the total number of students who have average and low mastery in each indicator.

2) The indicator is not tested in the item.

$n$ is the number of students.

Table 1 shows that the percentage of students who have high mastery in each indicator tested for each question was under $50 \%$. In general, this number shows that most students still experienced difficulty for each indicator of mathematical 
connection ability. For Problem 1, Connections, where A Implies the students perceived B (IM) as the most difficult indicator, where $73.68 \%$ of the students experienced difficulty in this indicator. For Problem 2, however, the most difficult indicator perceived by the students was connection showing that $\mathrm{A}$ is a procedure for doing B (PD), where $73.68 \%$ of students experienced difficulty in this indicator. For Problem 4, when compared to Problem 1 and Problem 2, the percentage of student difficulties for each indicator of mathematical connection ability was much higher. Of the four mathematical connection indicators tested in Problem 4, more than $80 \%$ of the students had difficulty, and even $97.37 \%$ of the students had difficulty in the part-whole relationships (PWR) indicator. For the PWR indicator, in particular, Problem 1 and Problem 2 have not accommodated this indicator, and therefore, we could not compare the students' difficulty for this indicator in Problem 3. The fact that the PWR indicator reached the highest percentage showed that the students experienced great difficulty in constructing answers using this indicator. Overall, we concluded that the students' mathematical connection difficulties occur in all indicators where PWR is the most difficult indicator, and PD is the second most difficult indicator for the students. The comparison between the students who had mastered and those who faced difficulties in making mathematical connections can be seen in Figure 1.

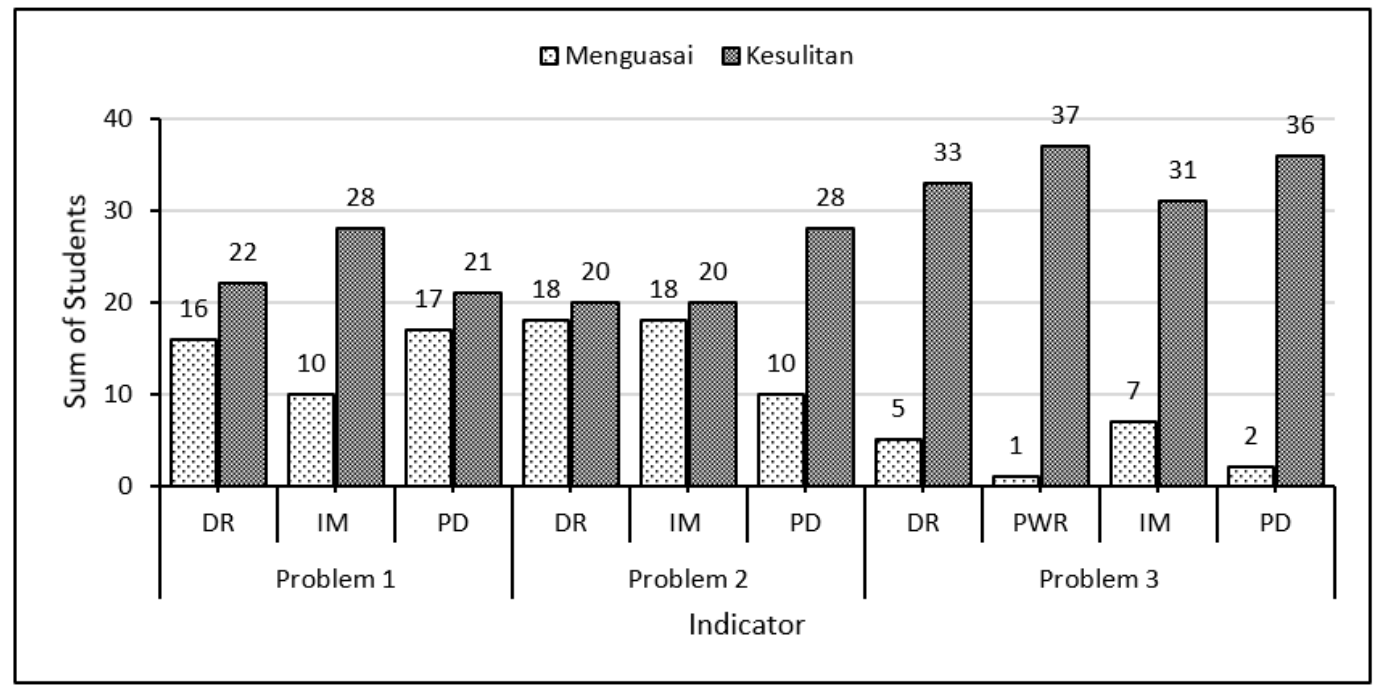

Figure 1. The comparison between the students who had mastered and those who faced difficulties of a mathematical connection

Figure 1 shows that the gap between students who had mastered the indicators and those who had not mastered the indicators was too big, especially in Problem 3. From Figure 1, we can see that the number of students who have not mastered the indicators is more prominent than those who have mastered the indicators of mathematical connection in each mathematics problem. Meanwhile, the gap for DR, PWR, PD indicators in all problems (Problem 1, Problem 2, and Problem 3) looked different. Thus, we conclude that for each mathematical connection indicator in each given problem, the number of students who experienced difficulty is higher than those who did not experience it. 
Qualitative data were also collected to confirm the findings. Based on the results of qualitative data reduction from students' interviews, we present some difficulties faced by the students in solving mathematical connection problems in Table 2.

Table 2. Identification of students' difficulties in making mathematical connections when solving problems

\begin{tabular}{|l|l|}
\hline \multicolumn{1}{|c|}{ Identification of Student Difficulty } & \multicolumn{1}{c|}{ Conclusion } \\
\hline $\begin{array}{c}\text { The students were unfamiliar with mathematical } \\
\text { connection problems. }\end{array}$ & $\begin{array}{l}\text { The students were not well } \\
\text { trained to solve mathema- } \\
\text { The students had difficulty in reading mathematical } \\
\text { patterns. }\end{array}$ \\
$\begin{array}{l}\text { theal connection problems } \\
\text { because of a lack of fami- } \\
\text { concepts. }\end{array}$ & \\
The students had difficulty in mathematic manipulation. & \\
\hline $\begin{array}{l}\text { The students did not understand several terms in the } \\
\text { problems. }\end{array}$ & $\begin{array}{l}\text { The students lacked con- } \\
\text { ceptual understanding. }\end{array}$ \\
$\begin{array}{c}\text { The students had difficulty in understanding the } \\
\text { problems completely. }\end{array}$ & \\
The students found it hard to identify important points \\
$\begin{array}{l}\text { from the problems. } \\
\text { The students forgot mathematical formulas. }\end{array}$ \\
\hline $\begin{array}{l}\text { The problems included too long words. } \\
\text { The problems required repeated reading. }\end{array}$ \\
\hline
\end{tabular}

Based on Table 2, we can understand that there are three main causes of students' difficulties in solving mathematical connection problems. The first is a lack of familiarity with mathematical connection problems, as seen in the following excerpts of student interviews.

"... I've never worked on a problem about fractions like in Problem 1." (Student 3)

"... I've never met a problem about a circle with another circle. A problem with a circle usually asks for tangents only. That's not about a circle intersecting another circle. The problem is difficult and unfamiliar to me." (Student 1)

The student interviews showed that so far, the students were only used to working on routine problems. Thus, they faced difficulty when doing non-routine problems, such as mathematical connection. Besides, they had difficulty in reading mathematical patterns, as expressed by two students in the following interview excerpts.

"... if we can find the pattern, the trigonometric identity is actually easy, but it's difficult for me to find the pattern because I don't have the good sense to do that." (Student 12)

"... I have difficulty seeing the pattern because of its fraction, and in my opinion, solving linear equations in this problem is very difficult." (Student 10)

The difficulty of linking concepts and manipulating mathematical operations caused the students to fail in their attempt to determine the next procedure for solving the problem, as illustrated in the following interview excerpts. 
"... the problem is not too confusing, but I just don't really understand the trigonometric identity and quadratic equation, then I find it hard to associate them." (Student 5)

"... I stopped at A and B because not find the comparison to calculate the value of $A$ and B." (Student 12)

Lack of conceptual understanding is one of the causes of the students' difficulty in solving mathematical connection problems, as stated by the students in the following excerpts.

"... I've difficulty in this problem; I don't understand the meaning of 'radius' and also the problem in general. So, I have no idea what the problem means." (Student 2)

"... I'm having a hard time understanding the problem; applying the trigonometric identity is quite difficult for me." (Student 10)

"... I don't understand about calculating the area of a circle, and I find it hard to separate the parts of the circle." (Student 5)

The student interviews proved that the students were still weak in the basic concepts of mathematics. In this case, they did not know the term 'radius' and how to calculate the area of a circle. Their low comprehension of such fundamental concepts caused them to have difficulty in understanding the purpose of the problem. Therefore, they failed to plan the correct procedure for solving the problem.

One of the common challenges faced by the students in problem-solving activities was that they were lazy to read word problems. The following excerpts illustrate this.

"... the word problem consisted of long sentences that demanded a lot of concentration on understanding the points. Well, I can understand the points. So, I separated the points first and then calculated the area." (Student 9)

"... what was asked in the problem was actually quite simple, but the description was not straightforward." (Student 11)

It appeared that the students did not enjoy reading the context or rather long information. This condition led to difficulty in understanding the problem as a whole and also planning mathematical procedures used to solve the problem. As a result, the students' progress in problem-solving related to mathematical connections would be hindered. To illustrate the students' difficulties in making mathematical connections in solving mathematical problems, we will present examples of cases of student difficulties for each indicator of mathematical connection in the next section.

Table 1 shows that the percentage of students who had difficulty in mathematical connections for each indicator was higher than those who had no difficulty. Although the gap between these two groups varied for the three types of problems given, the percentage of students who had difficulty always dominated 
those who had no difficulty. In the next section, we will describe some cases regarding the student difficulty in mathematical connections for each indicator.

\subsection{Different Representation (DR) as a form of a mathematical connection}

Of the three problems given to the students, the average percentage of students who experienced difficulty for different representations (DR) indicator was $65.79 \%$. This percentage clearly shows that most students still experienced difficulty in applying this indicator. We present an example of student difficulty in this indicator in Figure 2.

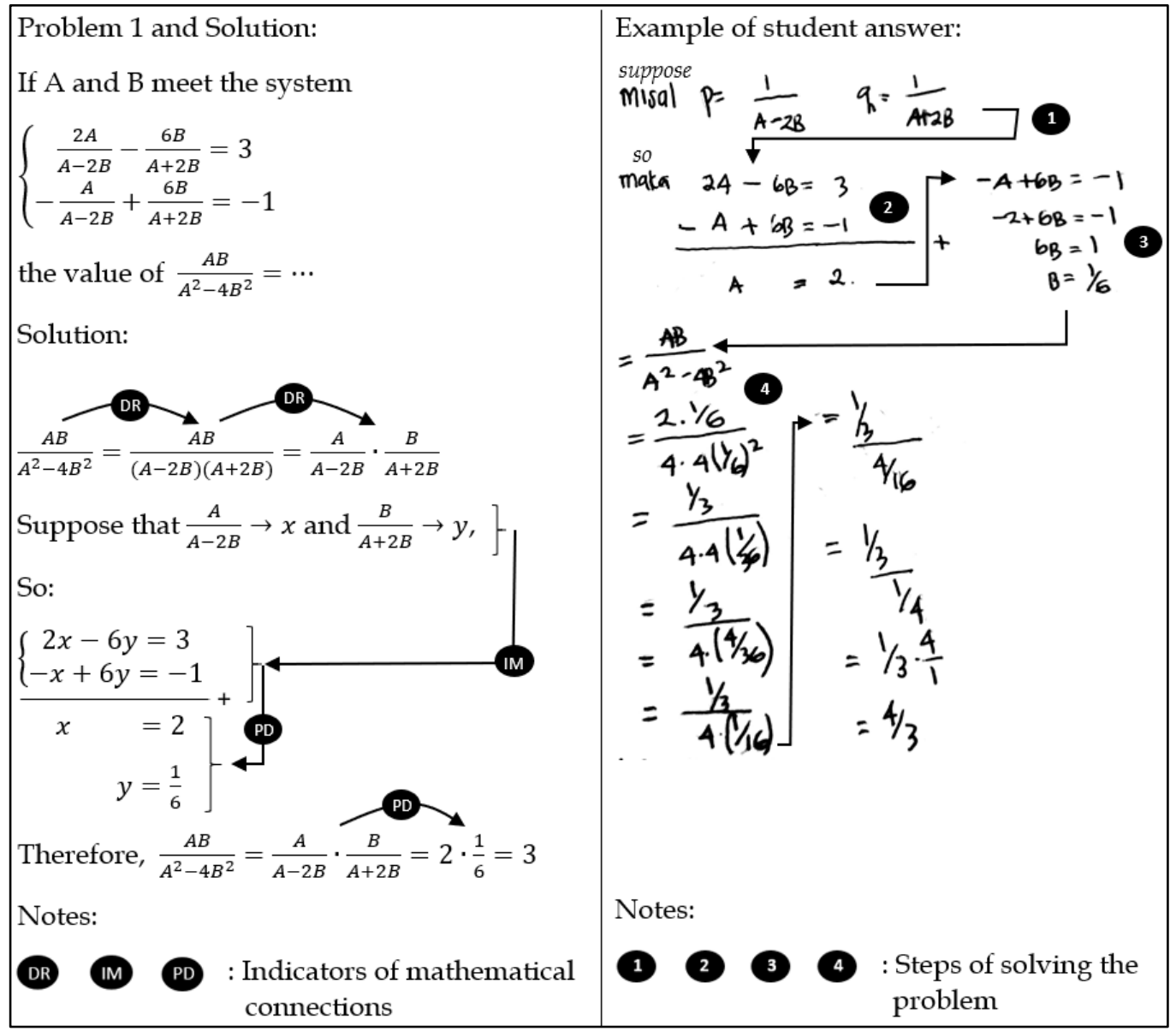

Figure 2. Example of student answer with difficulty in Different Representation (DR)

The example of student answer in Figure 2 shows that this student failed to solve the problem correctly. The failure started when the student made a mistake in designing a mathematical model appropriate to the context of the problem. In step 1 , the student defined two new variables, namely $p$ and $q$, where $p=\frac{1}{A-2 B}$ dan $q=\frac{1}{A+2 B}$. It can be observed that these two variables could not be linked to the two initial equations found in Problem 1. Also, in step 2, it shows that the equation model made was out of sync with the results obtained in stage 1 . Based on this finding, it is clear that the student's problem occurred when he was not able to represent the form $\frac{A B}{A^{2}-4 B^{2}}$ Into another form, and therefore incorrectly took another procedure to solve Problem 1. 


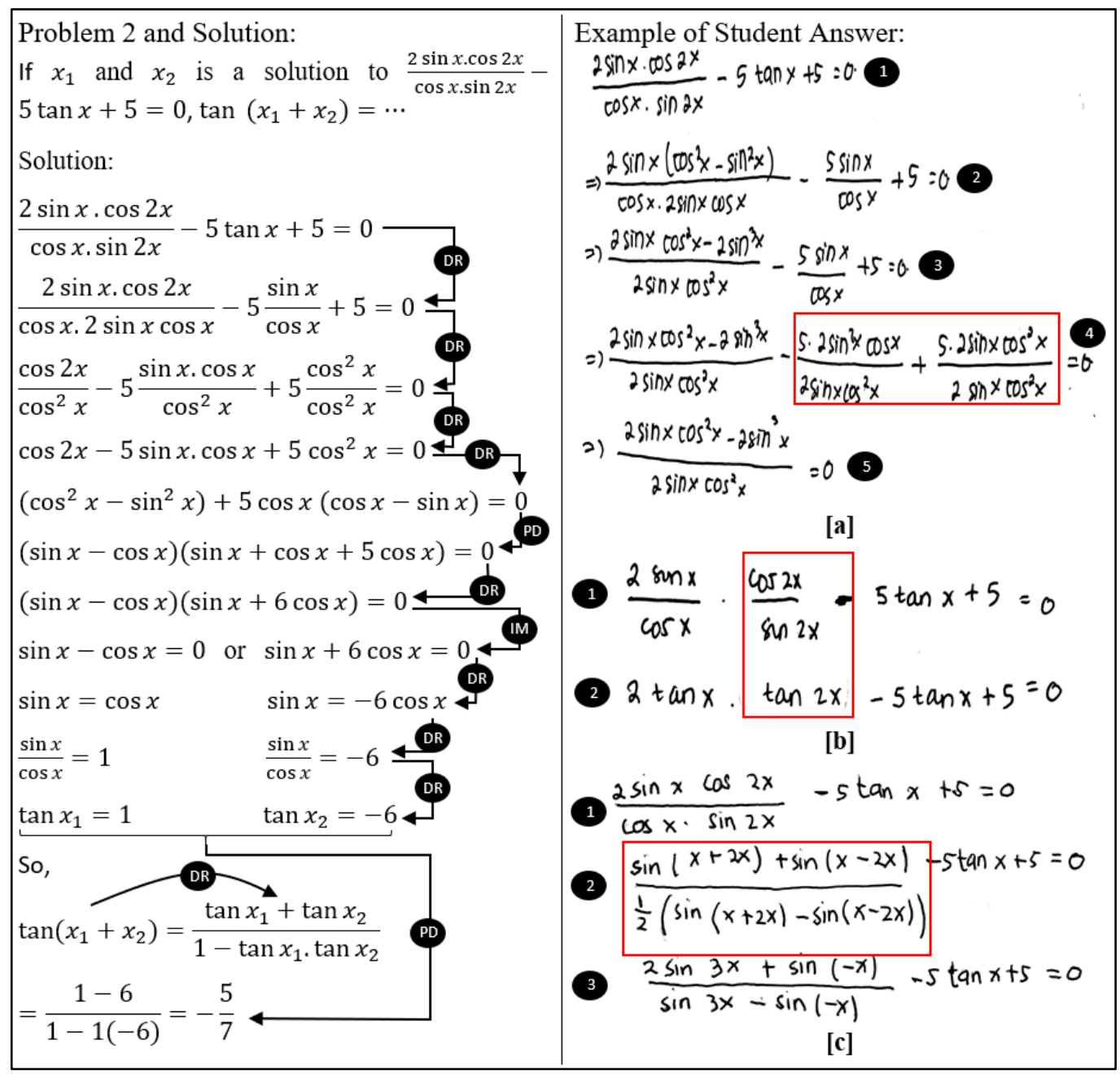

Figure 3. Another example of student answer with difficulty in Different Representation (DR)

In Figure 3, we present another example of student difficulty in the different representations (DR) indicator. In Figure 3 [a], the error in representing a different form of trigonometric equation occurred in step 4 (inside the box). Likewise, the example of the student's answer in Figure $3[b]$, in the red box, it is clear that students incorrectly changed the form $\frac{\cos 2 x}{\sin 2 x}$ into $\tan x$. Meanwhile, in Figure 3 [c], the error began in step 2, which the student manipulated the form of $2 \sin x \cdot \cos 2 x$ and $\cos x \cdot \sin 2 x$ by using the formula for multiplying sine and cosine, and we can see the error in the red box. Examples of these errors provide empirical evidence that the students still encountered difficulties in the different representations (DR) indicator for solving mathematical connection problems.

\subsection{Part-Whole Relationships (PWR)}

In this study, the PWR indicator for solving mathematical connections problems was only found in Problem 3. The percentage of students who did not master this indicator was the highest among all of the indicators, at $97.37 \%$. This finding strongly indicated that in the context of the given problem, the students' ability to do part-whole relationships was still low. We present examples of student 
answers that indicate that they have difficulties with the PWR indicator in Figure 4.

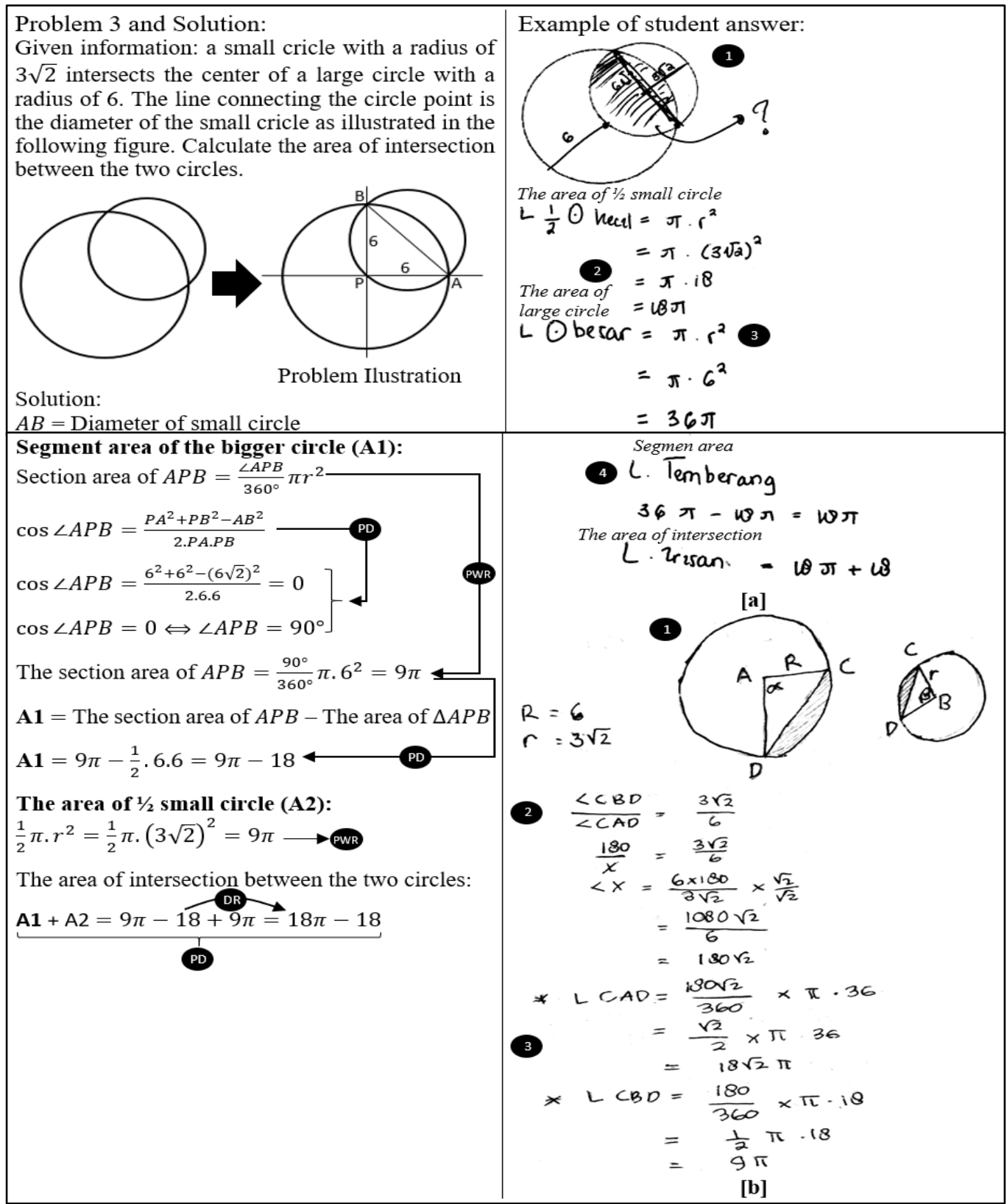

Figure 4. Example of the student answer with difficulty in Part-Whole Relationship (PWR) indicator

Figure 4 [a] shows that in step 1 , the student actually understood the meaning of Problem 3. However, it appeared that the students had difficulty calculating the segment area of a large circle. Based on the student's answer in Figure 4 [a], the student calculated the area of a large circle segment $=$ the area of a large circle the area of $1 / 2$ small circle. What the student did in this step indicated that he was not able to find the basic concepts used to calculate the area of segment (such as the rules of cosine, the area of the section, and the area of a triangle). In other words, the student encountered difficulty in finding part-whole relationships to 
find the segment range of the large circle. Next, Figure $4[\mathrm{~b}]$ showed the other example of a student's answer in solving Problem 3. In Figure $4[\mathrm{~b}]$ can be seen that the student found it hard to analyze the parts (see step 1) or the basic concepts used to find the whole solution to Problem 3 (see step 2 and step 3 ).

\subsection{Connections where A implies B (IM)}

IM indicator in mathematical connections is operationally visible when students can show a relationship that a mathematical concept results in another concept. In the three problems given to the students, each procedure for solving these problems contains an IM indicator. Based on the test of the three problems having the indicator, there were only $30.70 \%$ of the students who mastered the indicator. In contrast, the remaining $69.30 \%$ of the students did not master the indicator. We present the examples of student answers with difficulties in the connections where A implies B (IM) indicator in Figure 5.

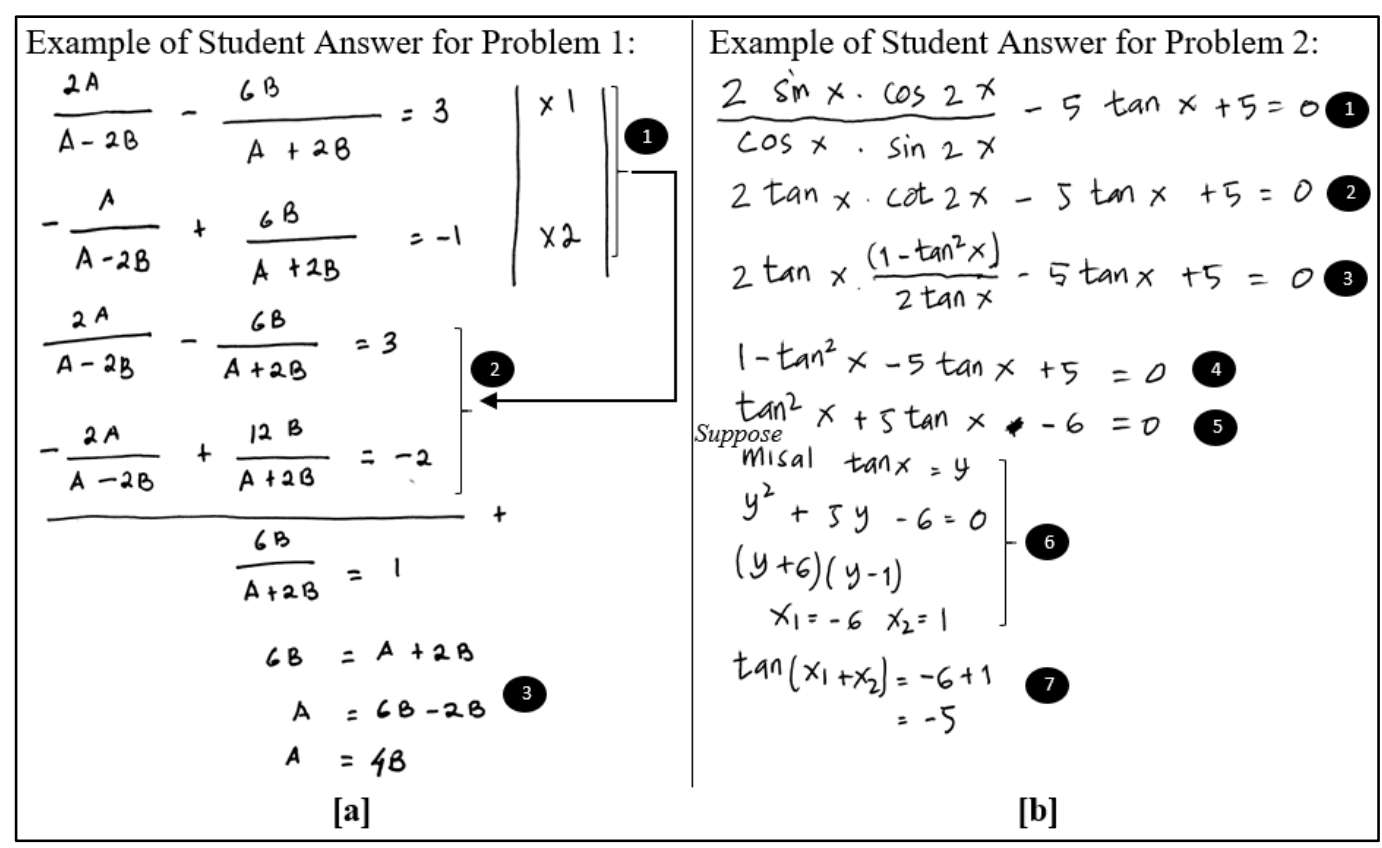

Figure 5. Example of student answer with difficulty in Connections Where A Implies B (IM) indicator

From algebra theory, the student's work in Figure 5 [a] was correct, but it was ineffective and required more time to find the final answer. If we compare the student's response in Figure 5 [a] with the solution to Problem 1 (see Figure 2), the difference is evident. The student's work in Figure 5 [a] clearly showed that he/she was not able to simplify the equations given. This finding is because the student was not able to manipulate the form from $\frac{A B}{A^{2}-4 B^{2}}$ into $\frac{A}{A-2 B} \times \frac{B}{A+2 B}$. As a result, the student failed to find another more straightforward concept (for example, doing mathematical modeling), leading to the discovery of the concept of a two-variable linear equation system. If the student succeeds in finding a more straightforward form of the two-variable linear equation system given, the procedure for solving Problem 1 will be more comfortable. 
Meanwhile, as seen in Figure $5[\mathrm{~b}]$, the student made a mistake in step 6. In this step, the student assumed/defined $\tan x=y$, so the trigonometric equation in step 5 could be changed into a quadratic equation $y^{2}+5 y-6=0$. By dividing it into factors (factorizing), the solutions from the quadratic equation were $y=-6$ dan $y=1$ (in Figure $6[\mathrm{~b}]$, the student wrote the solution as $x_{1}=-6$ and $x_{2}=1$ ). In this case, the solution of the quadratic equation found should be changed into the solution for the trigonometric equation. Because the student previously defined $\tan x=y$, the solution of the quadratic equation is converted into $\tan x=-6$ and $\tan x=1$. Due to some errors in performing the procedure, the final solution for determining the value of $\tan \left(x_{1}+x_{2}\right)$ was also incorrect. From this case, it is clear that the students still had difficulty in connecting a mathematical concept that results in other concepts.

\subsection{Connections showing that A is a Procedure for Doing B (PD)}

Another difficulty experienced by the students in mathematical connections is related to the indicator of connections showing that $\mathrm{A}$ is a procedure for doing $\mathrm{B}$ (PD). If the students were able to show that a mathematical procedure is applied to obtain another procedure, we consider them competent at this PD indicator. Each of the three problems tested contained the PD indicator, and we obtained the average percentage of the students who experienced difficulties for this indicator was $74.56 \%$. We present the examples of student answers with difficulty in PD indicator in Figure 6.

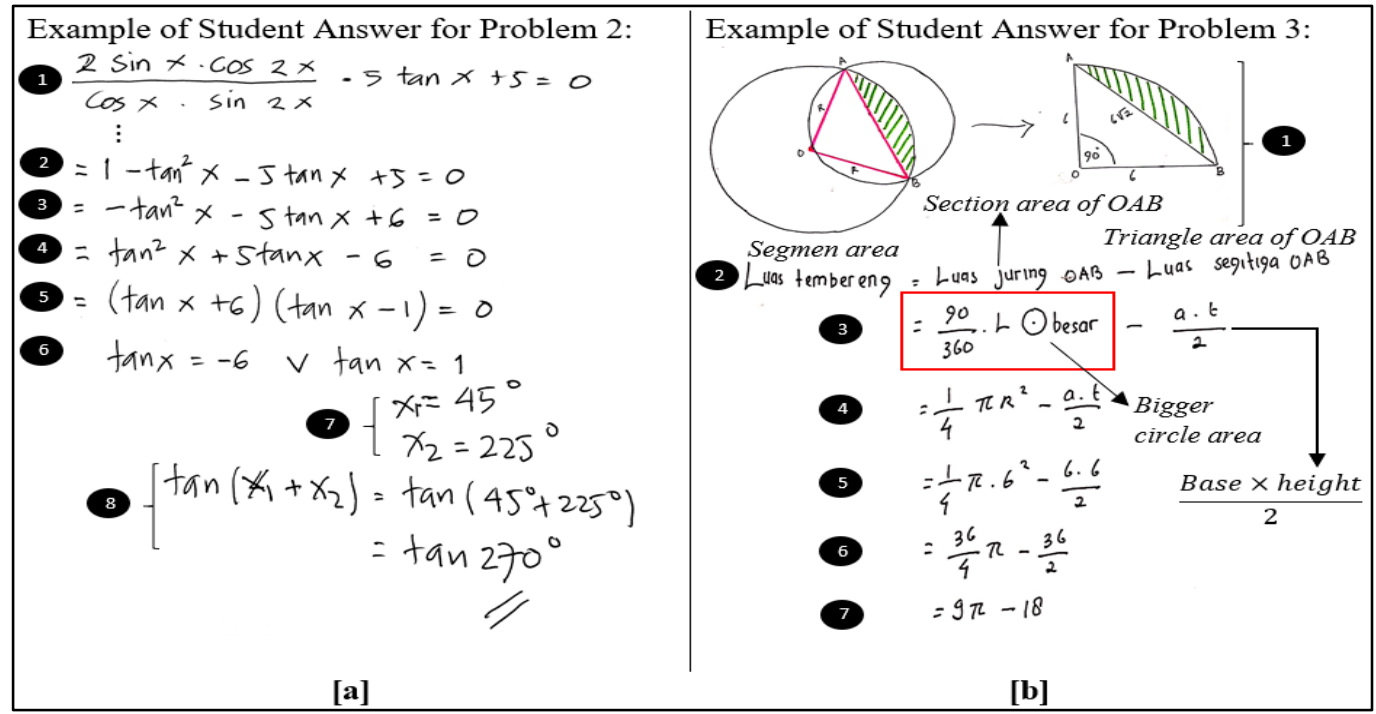

Figure 6. Example of student answer with difficulty in connections showing that $A$ is a Procedure for Doing B (PD) indicator

In Figure 6 [a], the student was able to find a solution to the trigonometric equation (see step 4 and step 5) resulted from the previous process, even though they did not assume first that $\tan x=x$. However, some errors still occurred in step 7 and step 8 , when the student associated that the value of $x$ is the angle (see step 7). The angles were then substituted with the equation $\tan \left(x_{1}+x_{2}\right)$ (see step $8)$, even though the intended final solution from Problem 3 was different. This finding clearly showed that the student was not able to connect between the 
procedures performed in steps 4,5 , and 6 with the equation $\tan \left(x_{1}+x_{2}\right)$ (step 8). Likewise, the student's answer in Figure $6[\mathrm{~b}]$, when the student calculated the area of a section (see step 3 , inside of the box), they wrote that the section area of the large circle was $\frac{90^{\circ}}{360^{\circ}} \times$ area of a large circle. However, the students did not show what procedure was applied to find a $90^{\circ}$ angle. According to the illustration drawn by the student (see step 1), a $90^{\circ}$ angle was determined based on the assumption that the triangle formed was a right triangle, not associated with cosine rules (see the solution of Problem 3 in Figure 4). This finding showed that the students were not able to show what procedure should be previously applied to calculate the section area of the circle.

\section{Discussion}

The results of this study generally indicate that most students have not mastered the mathematical connection skills well. For each mathematical connection indicator, most students have mastered the different representation indicator (DR) $(47.37 \%)$ and the connection where A implies B (IM) $(47.37 \%)$ in Problem 2. Whereas in other indicators, the percentage of students the master is still low. Many students have not mastered the mathematical connection indicators for each given mathematical problem, indicating clearly that most students still have difficulty making mathematical connections in solving mathematics problems. Students who have been able to make good mathematical connections show that they have a good understanding of using various mathematical concepts and procedures and their relationships to solve problems. This finding is consistent with the opinion of García-García and Dolores-Flores (2020) and Payton (2019). Conversely, students who have difficulties tend not to master the basic concepts and mathematical procedures needed to solve problems, as stated by students during interviews. Besides, the unfamiliarity of students in solving mathematics problems also causes them to experience difficulties. This unfamiliarity also impacts students' low interest in word problems, where students admit to being lazy to read problems with too long words, as stated by students during interviews.

The results of this study support the findings of several previous studies, which show that the students still experience difficulties in mathematical connection (Dolores-Flores et al., 2019; Kenedi et al., 2019; Lapp et al., 2010; Siregar \& Surya, 2017). Although previous studies involved participants at different levels, from elementary school to undergraduate levels, the obstacles faced by each participant were almost the same in general. Those obstacles consist of difficulty making representations in other forms, doing part-whole relationships, making implications, and showing the interrelationships between mathematical procedures. These mathematical connection difficulties also occurred in this study.

Of the four mathematical connection indicators studied in this study, most students had difficulty making the part-whole relationship (PWR). This finding is consistent with the findings of Mhlolo (2012) and García-García and DoloresFlores (2020). When doing PWR in solving mathematics problems, students should see the connection between general concepts through specific parts in the 
form of particular examples (Mhlolo, 2012). In this case, we understand that students are considered capable of making PWR if they apply specific concepts or procedures properly as part of the general concept to be completed. However, in this study, most students failed to do this. To overcome it, according to Mhlolo (2012), students need to be accustomed to doing and expressing generalizations both through deductive and inductive reasoning patterns. When students have good deductive and inductive reasoning skills, we expect that they will be able to do PWR well when solving mathematics problems.

One of the critical factors in making a mathematical connection is a deep understanding of its concept (Dolores-Flores et al., 2019; García-García \& DoloresFlores, 2018; Silver et al., 2009) and obtaining such conceptual understanding also needs mathematical connections (Anthony \& Walshaw, 2009). Dolores-Flores et al. (2019) believed that poor understanding of concepts to be the leading cause of the students' difficulty in making mathematical connections. As also confirmed from the interview conducted in this study, almost all of the students experiencing difficulties in making mathematical connections claimed that they did not understand the mathematical concepts needed to solve mathematical connection problems. For that reason, mathematics learning in the classroom should be focused on how to instill mathematical concepts in students to develop other mathematical skills.

Lack of familiarity with mathematical connection problems also caused difficulties in solving the problems. Mhlolo et al. (2012) suggest that most students lack the opportunity to deepen the understanding of mathematical connections. Besides, the books used have not yet been explicitly linked to the topics with various contexts, mathematics with real-life, and thus hinder the students from developing their mathematical connection skills (Salout et al., 2013). In this case, Baki, Çathoğlu, Coştu \& Birgin. (2009) recommend the need to make changes in the mathematics class in terms of content and context that must be applied.

The findings of this study have implications for the development of the pedagogy of mathematics learning. We believe that the factors that cause student difficulties in making mathematical connections when solving mathematics problems can be used as a framework for teachers in designing mathematics learning. As stated by García-García and Dolores-Flores (2020), what students do and communicate when solving mathematics problems involving mathematical connections is essential as a reflection to improve the quality of learning. At least the research findings have implications regarding the importance of teachers developing skills in facilitating students to make mathematical connections and best practices that can be applied to develop students' connection skills.

The teacher's pedagogical competence in training the students to solve mathematical connections also needs immediate attention. It is crucial to ensure that the teacher is well prepared and has confidence that the students have sufficient initial abilities to develop various mathematical skills. Bowen (2014) reports that teachers tend to be hesitant about using their knowledge of mathematical connections because they doubt their student abilities. For this 
reason, instilling confidence in teachers that their students can develop their ability in mathematical connection is very important. Besides, lack of assistance among the teachers regarding the planning and implementation of learning that facilitates students to make mathematical connections (Monroe \& Mikovch, 1994) is of concern mainly to policymakers in the field of education.

We can make various efforts to improve student ability in mathematical connections. As stated by NCTM (2000) that mathematical connection is a tool in problem-solving. This statement means that practicing problem-solving skills in learning mathematics participates indirectly in students' practicing mathematical connection skills. Various studies have reported that some learning models were effective to develop student problem-solving skills such as Problem-Based Learning (PBL) (Kartikasari \& Widjajanti, 2017; Malasari, Nindisari \& Jaenudin, 2017), collaborative problem-based learning strategy (Widjajanti, 2013), as well as using varied methods in learning such as direct learning, demonstration, practice and exercise, and also using modified instructional media (Jannah, Apriliya \& Karlimah, 2017). Also, it is crucial to give the students more activities of problemsolving so that they make a habit of it. Students of all ages are more motivated with problem situations that involve them and their classmates (WelchmanTischler, 1992); use three-dimensional manipulatives (Safi \& Desai, 2017); and use proof approaches (Jiang \& O'Brien, 2012). Another strategy that can be applied is using writing strategies in learning mathematics such as making drawings, pictures, tables, and graphs; providing a clear explanation of problem-solving methods and justifications of processes; and doing a reflection on learning (Haltiwanger \& Simpson, 2013). The use of math software such as GeoGebra has also been recommended to develop students' mathematical connection skills (Zengin, 2019)

Although this study succeeded in uncovering the types of mathematical connection difficulties experienced by students when solving mathematics problems and their causes, this study has not revealed the relationship between students' academic performance levels and difficulties. This limitation provides an opportunity for future research to focus on uncovering the relationship between types of mathematical connection difficulties and the level of student academic performance. Besides, this study's mathematical problems do not represent all mathematics topics studied at the high school level. Thus, to strengthen this study's findings, it is necessary to replicate this study by using mathematical problems on other topics.

\section{Conclusions and Implications}

Based on the study results and discussion, we concluded that the students still experienced difficulties in making mathematical connections when solving mathematics problems. These difficulties included making a different representation as a form of mathematical connections, part-whole relationships (hierarchical nature of concepts), connections that show $\mathrm{A}$ is a procedure for doing $\mathrm{B}$ (logical reasoning), and connections showing that $\mathrm{A}$ is a procedure for doing $\mathrm{B}$ (algorithms). In general, the indicators of mathematical connection difficulties experienced by the students as follows. First, lack of familiarity in solving 
mathematical connection problems characterized by difficulties in recognizing mathematical patterns, linking mathematical concepts, and working out mathematical manipulations. Second, poor understanding of the concept characterized by difficulties in understanding some mathematical terms, comprehending the whole problem, identifying essential points of the problem, applying mathematical formulas. Third, the lack of interest in word problems.

Our research findings are useful for educators in designing mathematics learning that facilitates the development of students' mathematical connections skills. Educators can use our findings to construct a framework to rearrange learning objectives, adjust the depth of learning topics, select mathematics contents and contexts, choose innovative strategies, consider the use of technology, even design assessments that consider mathematical connections. We recommend that the topics used to teach mathematics contain problem-solving activities that link some mathematical concepts and procedures and connect mathematics with other disciplines and real-life situations. Regarding the limitations of this study, we suggest that future research investigate the relationship between types of mathematical connection difficulties and the level of student academic performance. Furthermore, the researchers need to conduct investigations related to students' difficulties in making mathematical connections on other topics. We hope that replications can strengthen our research findings.

\section{References}

Agustini, R. Y., Suryadi, D., \& Jupri, A. (2017). Construction of open-ended problems for assessing elementary students mathematical connection ability on plane geometry. Journal of Physics: Conference Series, 895, 1-9. doi:10.1088/1742$6596 / 895 / 1 / 012148$

Albay, E. M. (2019). Analyzing the effects of the problem solving approach to the performance and attitude of first year university students. Social Sciences $\mathcal{E}$ Humanities Open, 1(1), 1-7. doi:10.1016/j.ssaho.2019.100006

Anthony, G., \& Walshaw, M. (2009). Effective pedagogy in mathematics. In J. Brophy (Ed.), Educational practices series - 19 (pp. 147-164). Geneva, Switzerland: IBE Publications Unit.

Apino, E., \& Retnawati, H. (2017). Developing instructional design to improve mathematical higher order thinking skills of students. Journal of Physics: Conference Series, 812, 1-7. doi:10.1088/1742-6596/812/1/012100

Apino, E., \& Retnawati, H. (2019). Creative problem solving for improving students' higher order thinking skills (HOTS) and characters. In E. Retnowati, A. Ghufron, M. Marzuki, K. Kasiyan, A. C. Pierawan \& A. Ashadi (Eds.), Character education for 21st century global citizens: Proceedings of the 2nd International Conference on Teacher Education and Professional Development (INCOTEPD 2017) (pp. 249-256). London, England: Routledge.

Appelbaum, P. (2000). Eight critical points for mathematics. Counterpoints, 110, 41-55. Retrieved from http://www.jstor.org/stable/42975936

Arjudin, A., Sutawidjaja, A., Irawan, E. B., \& Sa'dijah, C. (2016). Characterization of mathematical connection errors in derivative problem solving. IOSR Journal of Research \& Method in Education, 6(5), 7-12. doi:10.9790/7388-0605050712

Baki, A., Çathoğlu, H., Coştu, S., \& Birgin, O. (2009). Conception of high school students about mathematical connections to the real-life. Procedia Social and Behavioral Science, 1, 1402-1407. doi:10.1016/j.sbspro.2009.01.247

Berry, J. S., \& Nyman, M. A. (2003). Promoting students' graphical understanding of the calculus. 
Journal of Mathematical Behavior, 22(4), 481-497. doi:10.1016/j.jmathb.2003.09.006

Bogdan, R. C., \& Biklen, S. K. (2007). Qualitative research for education: An introduction to theory and methods. Boston, MA: Allyn and Bacon.

Bowen, B. (2014). Second-career mathematics teachers' knowledge of mathematical connections. Journal of STEM Teacher Education, 49(1), 29-44. doi:10.30707/JSTE49.1Bowen

Businskas, A. (2008). Conversations about connections: How secondary mathematics teachers conceptualise and contend with mathematical connections. (Doctoral dissertation, Simon Fraser University, Burnaby, Canada). Retrieved from http://ir.lib.sfu.ca/handle/1892/10579

Blum, W., Galbraith, P. L., Henn, H. W., \& Niss, M. (2007). Modelling and applications in mathematics education. New York, NY: Springer.

Creswell, J. W. (2013). Qualitative inquiry and research design: Choosing among five approaches (3rd ed.). Thousand Oaks, CA: Sage Publications.

Dolores-Flores, C., Rivera-López, M. I., \& García-García, J. (2019). Exploring mathematical connections of pre-university students through tasks involving rates of change. International Journal of Mathematical Education in Science and Technology, 50(3), 369389. doi:10.1080/0020739X.2018.1507050

Eli, J. A., Mohr-Schroeder, M. J., \& Lee, C. W. (2013). Mathematical connections and their relationship to mathematics knowledge for teaching geometry. School Science and Mathematics, 113(3), 120-134. doi:10.1111/ssm.12009

English, L. D., \& Gainsburg, J. (2016). Problem solving in a 21st-century mathematics curriculum. In L. D. English \& D. Kirshner (Eds.), Handbook of international research in mathematics education (3rd ed.) (pp. 313-335). New York, NY: Routledge.

García-García, J., \& Dolores-Flores, C. (2018). Intra-mathematical connections made by high school students in performing calculus tasks. International Journal of Mathematical Education in Science and Technology, 49(2), 227-252. doi:10.1080/0020739X.2017.1355994

García-García, J., \& Dolores-Flores, C. (2020). Exploring pre-university students' mathematical connections when solving calculus application problems. International Journal of Mathematical Education in Science and Technology, 51(7), 1-25. doi:10.1080/0020739X.2020.1729429

Hadi, S., Retnawati, H., Munadi, S., Apino, E., \& Wulandari, N. F. (2018). The difficulties of high school students in solving higher-order thinking skills problems. Problems of Education in the 21st century, 76(4), 520-532. doi:10.33225/ pec/18.76.520

Haltiwanger, L., \& Simpson, A. M. (2013). Beyond the write answer: Mathematical connections. Mathematics Teaching in the Middle School, 18(8), 492-498. doi:10.5951/mathteacmiddscho.18.8.0492

Hodge, B. (2003). Logical thinking in mathematics: From oz to awe! Research and Teaching in Developmental Education, 19(2), 41-46. Retieved from http://www.jstor.org/stable/42802166

Jannah, R. R., Apriliya, S., \& Karlimah, K. (2017). Didactical design material units of distance and speed to developed mathematical connection in elementary school. IOP Conference Series: Materials Science and Engineering, 180, 1-9. doi:10.1088/1757$899 X / 180 / 1 / 012022$

Jiang, Z., \& O'Brien, G. E. (2012). Multiple proof approaches and mathematical connections. The Mathematics Teacher, 105(8), 586-593. doi:10.5951/mathteacher.105.8.0586

Kartikasari, A., \& Widjajanti, D. J. (2017). The effectiveness of problem-based learning approach based on multiple intelligences in terms of student's achievement, mathematical connection ability, and self-esteem. Journal of Physics: Conference Series, 812, 1-8. doi:10.1088/1742-6596/812/1/012097

Kenedi, A. K., Helsa, Y., Ariani Y., Zainil, M., \& Hendri, S. (2019). Mathematical connection of elementary school students to solve mathematical problem. Journal on Mathematics Education, 10(1), 69-80. doi:10.22342/jme.10.1.5416.69-80

Lapp, D. A., Nyman, M. A., \& Berry, J. S. (2010). Student connections of linear algebra concepts: An analysis of concept maps. International Journal of Mathematical Education in Science and Technology, 41(1), 1-18. doi:10.1080/00207390903236665 
Leikin, R., \& Pitta-Pantazi, D. (2013). Creativity and mathematics education: The state of the art. ZDM Mathematics Education, 45, 159-166. doi:10.1007/s11858-012-0459-1

Lince, R. (2016). Creative thinking ability to increase setudent mathematical of junior high school by applying models numbered heads together. Journal of Education and Practice, 7(6), 206-212. Retrieved from https://iiste.org/Journals/index.php/JEP/article/view/29109/29873

Malasari, P. N., Nindisari, H., \& Jaenudin, J. (2017). A development of mathematical coonecting ability of students in junior high school through a problem-based learning with course review Horay method. Journal of Physics: Conference Series, 812, 1-7. doi:10.1088/1742-6596/812/1/012025

Mhlolo, M. K. (2012). Mathematical connections of a higher cognitive level: A tool we may use to identify these in practice. African Journal of Research in Mathematics, Science and Technology Education, 16(2), 176-191. doi:10.1080/10288457.2012.10740738

Mhlolo, M. K., Venkat, H., \& Schäfer, M. (2012). The nature and quality of the mathematical connections teachers make. Pythagoras, 33(1), 1-9. doi:10.4102/pythagoras.v33i1.22

Monroe, E. A., \& Mikovch, A. K. (1994). Making mathematical connections across the curriculum: Activities to help teachers begin. School Science and Mathematics, 94(7), 371-376. doi:10.1111/j.1949-8594.1994.tb15697.x

Moon, K., Brenner, M. E., Jacob, B., \& Okamoto, Y. (2013). Prospective secondary mathematics teachers' understanding and cognitive difficulties in making connections among representations. Mathematical Thinking and Learning, 15(3), 201-227. doi:10.1080/10986065.2013.794322

Mwakapenda, W. (2008). Understanding connections in the school mathematics curriculum. South African Journal of Education, 28(2), 189-202. doi:10.15700/saje.v28n2a170

NCTM. (2000). Principles and standards for school mathematics. Reston, VA: Author.

Ndiung, S., \& Nendi, F. (2018). Mathematics connection ability and students mathematics learning achievement at elementary school. SHS Web of Conferences, 42(9), 1-5. doi:10.1051/shsconf/20184200009

Osman, S., Yang, C. N. A. C., Abu, M. S., Ismail, N., Jambari, H., \& Kumar, J. A. (2018). Enhancing students' mathematical problem-solving skills through bar model visualisation technique. International Electronic Journal of Mathematics Education, 13(3), 273-279. doi:10.12973/iejme/3919

Özgen, K. (2016). A theoretical study on the mathematical connection. In W. Wu, M. T. Hebebci, \& O. T. Öztürk (Eds.), International Conference on Research in Education and Science (pp. 220-230). Bodrum, Turkey: ICRES Publishing. Retrieved from https:// www.2016.icres.net/ICRES_Proceeding_Book.pdf?rnd=333040543

Palmér, H., \& Van Bommel, J. (2020). Young students posing problem-solving tasks: What does posing a similar task imply to students? ZDM Mathematics Education, 52(4), 743-752. doi:10.1007/s11858-020-01129-x

Partnership for 21st Century Learning. (2019). Framework for 21st century learning. Retrieved from http://static.battelleforkids.org/documents/p21/P21_Framework_Brief.pdf

Payton, S. (2019). Fostering mathematical connections in introductory linear algebra through adapted inquiry. ZDM Mathematics Education, 51(7), 1239-1252. doi: 10.1007/s11858-019-01029-9

Rafi, I., \& Retnawati, H. (2018). What are the common errors made by students in solving logarithm problems? Journal of Physics: Conference Series, 1097(1), 1-9. doi:10.1088/1742-6596/1097/1/012157

Safi, F., \& Desai, S. (2017). Promoting mathematical connections using three-dimensional manipulatives. Mathematics Teaching in the Middle School, 22(8), 488-492. doi:10.5951/mathteacmiddscho.22.8.0488

Salout, S. S., Behzadi, M. H., Shahvarani, A., \& Manuchehri, M. (2013). Student's conception about the relation of mathematics to real-life. Mathematics Education Trends and Research, 2013(1), 1-7. doi:10.5899/2013/metr-00009

Silver, E. A., Mesa, V. M., Morris, K. A., Star, J., \& Benken, B. M. (2009). Teaching 
mathematics for understanding: An analysis of lessons submitted by teachers seeking NBPTS certification. American Educational Research Journal, 46(2), 501-531. doi:10.3102/0002831208326559

Siregar, N. D., \& Surya, E. (2017). Analysis of students' junior high school mathematical connection ablility. International Journal of Sciences: Basic and Applied Research, 33(2), 309-320. Retrieved from https://gssrr.org/index.php/JournalOfBasicAndApplied/article/view/7363/3471

Suh, J., \& Seshaiyer, P. (2013). Mathematical practices that promote 21st century skills. Mathematics Teaching in the Middle School, 19(3), 132-137. doi:10.5951/mathteacmiddscho.19.3.0132

Van Zanten, M., \& Van den Heuvel-Panhuizen, M. (2018). Opportunity to learn problem solving in Dutch primary school mathematics textbooks. ZDM Mathematics Education, 50(5), 827-838. doi:10.1007/s11858-018-0973-x

Welchman-Tischler, R. (1992). Making mathematical connections. The Arithmetic Teacher, 39(9), 12-17. Retrieved from https://www.jstor.org/stable/41195343

Widjajanti, D. J. (2013). The communication skills and mathematical connections of prospective mathematics teacher: A case study on mathematics education students, Yogyakarta State University, Indonesia. Jurnal Teknologi, 63(2), 39-43. doi:10.11113/sh.v63n2.149

Wijaya, A., Van den Heuvel-Panhuizen, M., Doorman, M., \& Robitzsch, A. (2014). Difficulties in solving context-based PISA mathematics tasks: An analysis of students' errors. The Mathematics Enthusiast, 11(3), 555-584.

Zengin, Y. (2019). Development of mathematical connection skills in a dynamic learning environment. Education and Information Technologies, 24(3), 2175-2194. doi:10.1007/s10639-019-09870-x 